\title{
La mujer judía en la España medieval
}

\author{
Enrique Cantera Montenegro *
}

\section{INTRODUCCIÓN}

Hace unos años comenzaba mi Comunicación presentada a las "V Jornadas de Investigación Interdisciplinaria sobre la mujer", organizadas por el Seminario de Estudios de la Mujer de la Universidad Autónoma de Madrid ${ }^{1}$, poniendo de manifiesto la enorme escasez de noticias que nos ofrecen las fuentes documentales para profundizar en el estudio de la condición de la mujer judía en los reinos hispanocristianos de la Edad Media. Unos años después no cabe sino insistir en lo mismo, de tal modo que si ya resulta difícil, por esta misma escasez de noticias documentales, progresar en el conocimiento de la historia de la mujer cristiana en el marco de la sociedad hispana medieval, las dificultades se multiplican con respecto a la mujer judía, en virtud de las peculiares condiciones familiares, religiosas y sociales en las que se desarrolla su vida.

A esta parquedad de la información de las fuentes documentales es a la que, en mi opinión, obedece la ausencia, prácticamente absoluta, de estudios y trabajos de investigación sobre la condición de la mujer judía en la España de la Edad Media; no obstante, es posible que la explica-

* UNED.

1 Esta comunicación, titulada «Actividades socio-profesionales de la mujer judia en los reinos hispanocristianos de la Baja Edad Media", ha sido publicada en el libro colectivo El trabajo de las mujeres en la Edad Media hispana, Colección Laya, núm. 3, Madrid 1988, págs. 321-345. 
ción se encuentre también en el hecho de que el reciente auge de los estudios sobre historia de la mujer no ha alcanzado todavía el marco concreto de los estudios sobre las minorías étrico-religiosas, al menos por cuanto se refiere a la historiografía hispana.

En definitiva, el objetivo de este trabajo no es, ni por el momento podría ser otro, que el de presentar un cuadro general sobre las condiciones en que se desarrolla la vida y la actividad de la mujer judía en la España medieval.

Con carácter general conviene recordar que, aun cuando lógicamente existen matices diferenciadores, las condiciones de vida de la mujer judia hispana son muy similares a las de la mujer judía de las comunidades hebreas de los restantes reinos europeos, ya que la religión, auténtico motor y guia de la vida del judio medieval, impone unos mismos condicionantes.

Por otra parte, existen también similitudes importantes entre la condición de la mujer judia y la de la mujer cristiana en los reinos hispanocristianos de la Edad Media, si bien con diferencias de matiz que creo que quedarán de manifiesto a lo largo del trabajo.

A la hora de presentar este cuadro general sobre las condiciones de vida de la mujer judía hispana se distinguirá claramente entre las condiciones en que se desarrolla su "vida privada" y las condiciones en que se desarrolla su "vida pública".

\section{LA MUJER JUDÍA HISPANA EN SU VIDA PRIVADA}

\subsection{La mujer en el seno de la familia judía hispana}

En las comunidades hebreas de la Edad Media el núcleo básico de organización social es la familia, entendida en sentido estricto o familia conyugal -el matrimonio con o sin hijos-, o en sentido amplio - todos los individuos ligados por los mismos lazos de sangre y parentesco-. Aun cuando no existen elementos suficientes que permitan asegurarlo con certeza absoluta, parece claro que desde la más remota antigüedad la familia judia se organiza según su "estricto régimen patriarcal», lo que 
en la Edad Media hispana puede observarse tanto en la frecuente omisión de la esposa y madre en las escasas noticias que la documentación medieval ha conservado sobre la familia judia, como en las referencias genealógicas y onomásticas ${ }^{2}$. Así, la individualización de la persona judía se realiza por la filiación, y ésta viene siempre dada por el nombre paterno ${ }^{3}$, siendo muy rara una filiación por línea femenina ${ }^{4}$. La onomástica contribuye también a reafirmar la hipótesis de la familia patriarcal, ya que por regla general los hijos mayores, fueran varones o hembras, reciben el nombre de sus abuelos paternos.

Así, pues, y en virtud de su carácter patriarcal, el varón ejerce la autoridad suprema de la familia judía ${ }^{5}$, en tanto que el papel de la mujer queda prácticamente limitado, al cumplimiento de las obligaciones derivadas de su condición de esposa y madre, así como a la realización de los trabajos domésticos. De este modo, en las relaciones familiares pueden apreciarse algunos rasgos de la manifiesta inferioridad jurídica de la mujer en la sociedad judia medieval.

En tanto permanecía soltera, la mujer se encontraba en una situación de inferioridad jurídica, estrictamente sometida a la autoridad del padre, o de un tutor en el caso de fallecimiento de éste. Al contraer matrimonio la mujer quedaba bajo la autoridad del marido, a quien debía obediencia, fidelidad y afecto. Para la educación moral, religiosa y civil de la mujer, el marido tenía una autoridad sin límites, de tal forma que, incluso, el Derecho penal no consideraba como punibles las heridas y los golpes infligidos por el marido a su mujer -lo mismo que los del padre al hijo menor de edad, o los del maestro al discipulo-, ya que el Derecho presupone que el castigo tiene como finalidad la corrección y enmienda.

Por otra parte, y como veremos más adelante con mayor detenimiento, todos los bienes que la mujer aportaba al matrimonio como dote,

${ }^{2}$ Estas circunstancias son también señaladas para la familia judia portuguesa por Maria José Pimenta Ferro Tavares, Os judeus em Portugal no século xv, Universidade Nova de Lisboa, 1982, pág. 227.

${ }^{3}$ Por ejemplo, Semuel ben Rabi Hanamaeel, vecino de Calahorra a principios del siglo XIV. "Ben" significa, como es bien sabido, "hijo de".

${ }^{4}$ Sólo en algún caso la filiación viene dada por línea materna, cuando la madre es conocida por un apodo especialmente significativo.

${ }^{5}$ La justificación de la superioridad del hombre sobre la mujer en la familia judía la encontramos en el capítulo III, versiculo 16, del Génesis, cliando Yahvéh, después del Pecado Original, dice a Eva: "Multiplicaré crecidamente los sufrimientos de tu gravidez; con sufrimiento parirás hijos. $Y$ tu propensión te inclinará a tu marido, el cual te dominará". 
asi como los que heredaba y los que adquiría con su trabajo, pertenecían al marido, quien podía disponer de ellos libremente, como si fueran de su entera propiedad. En estrecha conexión con todo ello, las mujeres casadas no tenían capacidad para realizar donaciones de bienes sin la autorización de su marido.

No obstante todo lo dicho hasta aquí, y a pesar de algunas burlas y sátiras misóginas ${ }^{6}$-algunas de origen no judío-, el sentimiento que rodea a la mujer es el de afecto y respeto. Es este el sentimiento que expresa de forma magnifica el poema "Eshet Hayil» («La mujer fuerte»), que se contiene en el capítulo XXXI, versículos 10-31, del Libro de los Proverbios ${ }^{7}$. Se trata de uno de los poemas más bellos de la Biblia, fuente de inspiración para obras como La perfecta casada de fray Luis de León o el De Institutione feminae christianae de Luis Vives, y en el que se traza el cuadro de la mujer judía ideal, constituyendo un auténtico abecedario de la buena ama de casa. Pese a que algunos autores han visto en este poema un sentido alegórico, de tal forma que con él se pretendería una glorificación de la Ley judia, del Shabat o de la "Shekhina" (la "presencia divina", en círculos cabalísticos), nada le priva del innegable homenaje que rinde a la mujer, "revestida de fuerza y dignidad", "que abre la boca con sabiduria", "cuya enseñanza es bondadosa", y "a la que sus hijos felicitan y su marido elogia".

${ }^{6}$ Por ejemplo, las que aparecen en los capítulos $\mathrm{V}$ y VII del Libro de los Proverbios, que tratan sobre la mujer adúltera.

7 Este poema dice así: “10. Una mujer fuerte, ¿quién la encontrará? Por cima de las personas se alza su valor. 11. Confía en ella el corazón de su marido y de ganancia no carece. 12. Proporciónale ella bien y no mal todos los días de su vida. 13. Procúrase lana y lino, y trabaja con la diligencia de sus manos. 14. Es como navios de mercader: de lejos trae sus viveres. 15. Levántase cuando aún es de noche, y distribuye la comida a su casa y la tarea asignada a sus criadas. 16. Piensa en un campo y lo adquiere, del fruto de sus manos planta una viña. 17. Ciñe vigorosamente sus lomos y fortalece sus brazos. 18. Comprueba que marcha bien su negocio, no se apaga durante la noche su lámpara. 19. Aplica sus manos a la rueca y sus palmas sostienen el huso. 20. Tiende su palma al desvalido y sus manos alarga al indigente. 21 . No teme para su casa la nieve, pues toda su casa está vestida de grana. 22. Hácese cobertores; de lino fino y púrpura es su vestido. 23. Conocido en las puertas es su esposo cuando se sienta con los ancianos del país. 24. Fabrica lienzo y lo vende, y proporciona ceñidores al mercader. 25. De fuerza y dignidad está revestida y sonríe al día por venir. 26. Su boca abre con sabiduría y enseñanza bondadosa hay en su lengua. 27. Vigila las idas y venidas de su casa y el pan de la ociosidad no come. 28. Levántanse sus hijos y la felicitan; su marido, y la elogia. 29. ¡Muchas hijas realizaron hazañas, más tú sobrepasas a todas ellas! 30 . Falaz es la gracia y vana la hermosura; la mujer que teme a Yahvéh, ésa ha de ser loada. 31. Dádle del fruto de sus manos y alábenla sus obras en las puertas." Sagrada Biblia, por J. M. ${ }^{a}$ Bover y F. Cantera Burgos. Madrid, Biblioteca de Autores Cristianos, 1961 (6. ${ }^{a}$ ed.), págs. 708-709. 
La religión judía consideraba al "matrimonio» como el estado social perfecto, de tal modo que una máxima talmúdica maldice al judio que deja pasar la edad de veinte años sin contraer matrimonio. Para el judaísmo la vocación del hombre y de la mujer debe ser la unión fecunda, lo que tiene su justificación en el precepto divino de "creced y multiplicaos" (Génesis, I, 28). Por ello continuamente se exaltan las instituciones de la familia y del matrimonio; en época postbíblica la legislación rabínica favoreció los matrimonios en edad temprana, de tal modo que la edad mínima para contraer matrimonio se fijaba en trece años para los varones $y$ en doce para las mujeres ${ }^{8}$.

Asi, pues, la mujer judia, al igual que la mujer cristiana, era educada primordialmente para el matrimonio y para la maternidad. Teniendo en cuenta que en el mundo medieval era fundamental la perpetuación del linaje, la mayor honra que a una mujer podía caber era el proporcionar descendencia a su marido. A ello se unía entre los judíos la imperiosa necesidad de procreación para perpetuar el grupo, a lo que muy probablemente pueda deberse la mayor fertilidad de los matrimonios judíos, con respecto a los matrimonios cristianos, en la España medieval ${ }^{9}$. Por ello, la esterilidad de un matrimonio era causa de deshonra para la mujer, y podía, incluso, ser motivo de la disclución del vínculo matrimonial.

Con la misma finalidad de favorecer la procreación, la ley judía permite la "poligamia", y éste parece que fue el estado matrimonial propio de los judios en la Antigüedad. Sin embargo, desde el siglo XI termina imponiéndose el "matrimonio monogámico" en todas las comunidades hebreas europeas, por la decidida acción de los autores rabínicos, que tenían como uno de sus objetivos prioritarios la mejora de la condición legal y social de la mujer. La poligamia persistió durante mayor tiempo en las comunidades del mundo mediterráneo, especialmente en el mediodía francés y en la Península Ibérica - todavía en el siglo XIII era práctica usual en las comunidades hebreas aragonesas-, pero a lo largo de la Baja Edad Media desapareció paulatinamente.

El "matrimonio judio" se sustenta en la "ketubah» o contrato nupcial otorgado por el futuro marido a la novia, en la que se regulan todas las

\footnotetext{
${ }^{8}$ La edad media de matrimonio de la mujer judía hispana se sitúa en torno a los quince 0 dieciséis años.

${ }^{9}$ En tanto que un matrimonio cristiano tenía por término medio tres hijos, un matrimonio judío cuatro.
} 
condiciones del matrimonio: se especifica la promesa de fidelidad, protección y sustento por parte del marido a la mujer, y se fijan la dote que entregará el novio a la novia y el ajuar que aportará ésta.

La "ketubah" se trata, en definitiva, de un documento que procuraba la protección de la mujer en el matrimonio. Esta pretensión de garantizar la condición de la mujer al contraer matrimonio queda claramente manifiesta en las "Taqqanot" u Ordenanzas redactadas en el año 1432 por una comisión de notables judios y de representantes de las aljamas del reino de Castilla que, bajo la presidencia de don Abraham Bienveniste, rabí mayor de los judíos de Castilla, y con el beneplácito de don Alvaro de Luna, se reunió en Valladolid con el fin de redactar unos estatutos que en adelante sirvieran como norma de gobierno para todas las comunidades hebreas castellanas. El capítulo tercero de estas "Taqqanot" se ocupa de la regulación del tema de los matrimonios, estableciendo diversas disposiciones que tratan de garantizar la condición de la mujer:

1. Se prohibe acudir a reyes $o$ a señores con el fin de obtener cartas que forzasen la voluntad de los contrayentes.

2. Se prohíbe hacerse acompañar de autoridades cristianas a fin de presionar a mujeres honradas a aceptar el matrimonio.

3. Los desposorios habrían de celebrarse en presencia de diez testigos, parientes y ancianos judíos (los "diez adultos de Israel»), y ante el padre o el hermano de la novia, que otorgaban el consentimiento al matrimonio, entregaban a la joven y bendecian las arras.

Por otra parte, en ocasiones los padres de la novia exigian del novio un compromiso formal de no repudiar nunca a su mujer. Asimismo era muy frecuente que en el contrato de esponsales el novio se comprometiera a tratar siempre bien a su esposa, lo que invita a pensar que los malos tratos a las mujeres por parte de sus maridos debian ser frecuentes, especialmente en los estratos sociales más bajos.

El matrimonio era, en general, más el resultado de una conveniencia que de un amor sincero entre los contrayentes. Con frecuencia en las familias más poderosas servía como sello de un compromiso entre dos familias, que muchas veces se suscribia siendo menores de edad los futuros contrayentes. De esta forma se conseguia estrechar lazos entre dos familias o se evitaba la dispersión del patrimonio familiar. Esta realidad provocó una fuerte endogamia en las familias más poderosas, con matrimonios frecuentes entre primos hermanos. 
Como ya he señalado anteriormente, la finalidad primordial del matrimonio era la "procreación", de tal modo que se asegurara la perpetuación del linaje.

Por ello, la ley judía creó una institución peculiar conocida con el nombre de "levirato", que aparece regulada en el capitulo XXV, versículos 5 y 6 del Deuteronomio: «5. Cuando unos hermanos vivan juntos y uno de ellos muera sin tener un hijo, la mujer del difunto no habrá de casarse fuera con hombre extraño; su cuñado se llegará a ella y la tomará por esposa y cumplirá con ella la ley del levirato. 6 . El primogénito que ella dé a luz deberá llevar el nombre del hermano difunto, para que su nombre no sea borrado de Israel.»

Asi pues, si una mujer quedaba viuda sin haber dado descendencia a su marido, uno de los hermanos del difunto debía contraer matrimonio con ella, una vez que hubieran transcurrido los tres meses de duelo obligado, y siempre que hubiera uno que pudiera cumplir con ello sin romper otro compromiso anterior.

Si habiendo un hermano del difunto en condiciones de contraer matrimonio no lo hiciera, ni la viuda ni él mismo podrían casarse en tanto ésta no le librara de la obligación mediante la ceremonia de la «haliza», regulada en los versículos 7 a 10 del capítulo XXV del Deuteronomio, y que tenía por objeto humillar públicamente al hermano del difunto, que se negaba a perpetuar su linaje:

«7. Pero si al hombre no le agrada tomar a su cuñada, ésta subirá a la puerta adonde los ancianos, y dirá: "Mi cuñado se niega a perpetuar el nombre de su hermano en Israel; no quiere cumplirme la ley del levirato." 8. Entonces los ancianos de aquella ciudad le llamarán para interpelarle. Si se presenta y dice: "No me agrada desposarme con ella". 9. Su cuñada se acercará a él en presencia de los ancianos, le quitará el zapato de su pie y le escupirá a la cara, y, tomando la palabra, dirá: "AAsí se hace con el hombre que rehusa edificar la casa de su hermano!" 10. Y se le apodará en Israel: "Familia del descalzado"”.

Pese a que no existe documentación suficiente que permita asegurar que el levirato se practicaba frecuentemente en las comunidades hebreas hispanas, todo hace pensar que asi debia ser, ya que en los escritos de los rabinos españoles hay frecuentes alusiones al levirato, otorgándole siempre prioridad sobre la "haliza». 
La esterilidad de un matrimonio podía ser causa de la ruptura del vínculo contractual. Así, la ley permitía que al cabo de diez años de relaciones infecundas el marido otorgara a su mujer "carta de repudio" o de "guete". Pese a esta permisividad de la ley, los autores rabínicos medievales -como hemos visto antes, abiertamente partidarios de la monogamia - consideran el divorcio como un atentado contra el matrimonio monogámico, incluso en los casos de ausencia de hijos.

La ley judia condena sin paliativos el "adulterio" pero, por el contrario, tolera el "concubinato", justificado por sus relativamente frecuentes referencias en la Biblia. Algo similar sucede en la sociedad cristiana medieval, en la que asimismo se toleraba.

El Talmud no resuelve con claridad el tema del concubinato, pero sí existe alguna alusión a él en los autores rabínicos; para éstos una concubina es una mujer con la que se cohabita y con la que existe una promesa matrimonial, pero a la que todavía no se ha otorgado la «ketubah", por lo que no se trata de la esposa legítima.

Diferente del concubinato era la simple "cohabitación", no regulada por la ley y que entraba en el ámbito de la moral. En estos casos la mujer tenía plena libertad para abandonar al hombre cuando lo deseara. En el caso de relaciones de este tipo entre amo y criada, la familia de ésta podía solicitar en cualquier momento la anulación del contrato de servicio doméstico que la ligaba a su amo. Precisamente fue la posibilidad de abusos sexuales de los señores con sus criadas, así como el temor al proselitismo religioso judío, lo que motivó las reiteradas prohibiciones de las autoridades eclesiásticas y de las Cortes bajomedievales castellanas para que los judíos tuvieran en sus casas criadas o nodrizas cristianas.

\subsection{La mujer judia hispana en el derecho de sucesión de bienes}

Según se ha señalado anteriormente, la mujer judía casada no era propietaria de ningún tipo de bienes, ya que todos pertenecían al marido. Sin embargo, las leyes judías castellanas eran en este apartado bastante más favorables para la mujer que la legislación hebrea en general. 
Así, en la legislación judia castellana sobre régimen de sucesión de bienes encontramos algunas disposiciones claramente favorables para la mujer, entre las que podrian destacarse las siguientes:

1. Alcanzada la pubertad, a los doce años y medio, la mujer tenia pleno derecho a recibir en propiedad lo que le correspondiera por herencia o por otro título legal.

2. Si un judío moría dejando un hijo varón y una o varias hijas sin casar, tendrían derecho a la herencia por partes iguales, y sólo si el varón era el primogénito tendría derecho a una porción doble en virtud del precepto bíblico que favorece la primogenitura. No obstante, a la muerte de la madre las hijas no tendrían ya ningún derecho a la herencia.

Por el contrario, si moría antes la madre las hijas tendrían los mismos derechos a la sucesión que los hijos, recibiendo también a la muerte del padre su parte correspondiente.

3. Si un judío moría dejando sólo hijas, éstas tendrian todas el mismo derecho a la sucesión, sin distinción alguna entre casadas y solteras.

Aunque con un carácter mucho más reducido geográficamente, se conserva un manuscrito de la primera mitad del siglo $\mathrm{XV}$, estudiado por el padre Llamas ${ }^{10}$, en el que se recogen unas "taqqanot" u ordenanzas sobre sucesión de bienes matrimoniales, redactadas para las aljamas hebreas de Toledo y Molina de Aragón, y en las que se contiene también alguna disposición muy favorable para las mujeres, como la que establece que al morir el marido, la viuda recibiría los bienes dotales en su integridad y la mitad de la herencia del marido, en tanto que sólo la otra mitad de la herencia sería para los herederos legítimos del cónyuge difunto.

Esta misma protección hacia la mujer en la legislación hebrea castellana queda también de manifiesto en la exención de tributación a las viudas cuyas rentas no sobrepasaran los cuatrocientos maravedies anua-

${ }^{10} \mathrm{P}$. J. Llamas, «Documentos para la historia jurídica de las aljamas hebreas de Toledo y Molina", Religión y Cultura, XIX, Monasterio de San Lorenzo de EI Escorial, 1932, págs. 263-276. 
les, según se establece en el capítulo IV de las "Taqqanot» de Valladolid de 1432. En este aspecto se igualaba a las viudas con los huérfanos solteros y con los lisiados.

Finalmente, las leyes judías castellanas prohibían al marido satisfacer sus deudas con los bienes que poseía de su mujer.

\subsection{La mujer judía hispana en el Derecho penal}

Desde el punto de vista penal, la legislación judía castellana protegía también de forma significativa a la mujer. Con carácter general, y más bien anecdótico, pese a que los pleitos y causas se despachaban siempre según riguroso orden de presentación, existía una cierta prelación, de forma que el pleito presentado por el menor de edad debía ser visto antes que el de la viuda; el de la viuda antes que el del sabio; el del sabio antes que el del ignorante; $y$ uel de la mujer antes que el del hombre».

Los delitos sexuales eran penados con suma dureza por la legislación judía: el adulterio se castigaba con la pena de azotes si la mujer era judia y soltera; si, por el contrario, era casada o pagana el hombre era castigado con la pena de muerte. Del adulterio cometido en campo abierto sólo se hacía responsable al varón, pues la ley presume que, como en los casos de violación, la mujer ha gritado pero nadie ha acudido en su socorro.

Los delitos de violación, por su parte, eran castigados con la pena de azotes.

Finalmente, la mujer judía conocía alguna restricción en lo que afecta al ejercicio del Derecho, ya que tenían prohibido desempeñar el oficio de juez, lo mismo que los paganos, los disminuidos físicos, los jugadores y los libertinos. 


\subsection{La mujer judía hispana en la vida religiosa}

Un aspecto absolutamente fundamental al estudiar la condición de la mujer judía en la España medieval es el de la religión, ya que si ésta constituía un elemento trascendental, qué duda cabe, en la vida del hombre medieval, mucho más entre los judíos para los que la religión no sólo constituía el centro y guía de toda su vivencia, sino que, junto con la raza, era un elemento de cohesión que les permitía conservar su identidad en el seno de la sociedad mayoritaria y dominante hispanocristiana, evitando su disolución como grupo social propio y diferenciado.

Desde los doce años la mujer quedaba obligada al cumplimiento de la ley ritual. Sin embargo, al contrario que los varones, la mujer estaba libre, como norma general, de los múltiples mandamientos religiosos positivos o "mizwot": así, no estaba obligada a hacer oraciones a hora fija ${ }^{11}$, ni a participar en la oración comunitaria, ni a cumplir con las ceremonias de las diversas festividades de la religión judia. Asimismo, la mujer no contaba para la constitución del "minyán" ${ }^{12}$, ni se la admitía como testigo ante el tribunal rabínico. En este sentido, en una relación de las principales ceremonias y práciicas religiosas judías, elaborada para uso de inquisidores, se dice textualmente:

“Las mugeres no heran obligadas a cosa alguna de rrezar, ni por ninguna manera se juntaban con los onbres, ni çient mugeres balían para cumplir el número tanto como un niño de teta, e las que heran devotas hellas se tenían su cámara junta a la sinoga para que estubiesen e un rrabi que les rreszase en rromanze todo lo que en la sinoga se rreçava en hebrayco; entre ellas no avía obligaçión de número" ${ }^{13}$.

En definitiva, y pese a que las mujeres solian iniciar la jornada con las bendiciones y abluciones rituales, no estaban obligadas a participar en la oración comunitaria. Si lo hacían, hombres y mujeres debían estar

$"$ Entre ellas el Semá Israel (=Escucha Israel), oración que recoge los principios fundamentales de la religión mosaica -equivalente, en cierto modo, al Credo cristiano- y que debe ser recitada por todo judio dos veces al dia, por la mañana y por la tarde.

12 Número mínimo de diez personas judias, varones mayores de trece años, imprescindible para la celebración del culto colectivo o público.

${ }_{13}$ Archivo Histórico Nacional, Inquisición, libro 1.254, fols. 153-172 (fol. 160 vuelto). 
rigurosamente separados. Aun cuando no es frecuente que las sinagogas ofrezcan una separación para hombres y mujeres, ya que por norma general las mujeres no solian acudir a la sinagoga, en ocasiones sí la presentan; en estos casos existen dos soluciones arquitectónicas:

1. La construcción de una o varias salas anexas al fondo de la sala principal de oración, separadas de ésta mediante un tabique ligero y móvil, llamado "mehiza». Esta es la solución comúnmente utilizada en las comunidades ashkenazíes.

2. La construcción de galerías altas, al modo de los triforios de las iglesias románicas. Esta es la solución que generalmente se emplea en las comunidades sefardies o hispanas (sinagogas de Toledo y Córdoba).

Un aspecto de gran interés del párrafo que se ha incluido un poco más arriba, tomado de la relación de prácticas judías para uso de inquisidores, es el que hace referencia a que un rabino rezaría con las mujeres en romance lo que en la sinagoga se rezaba en hebreo. Esto obedece a que la lengua utilizada por los judíos hispanos en la vida diaria era el romance, en tanto que el hebreo era tan sólo la lengua de la religión —de forma singular a lo que acontecía con el latín para la iglesia Católica y con el griego para la iglesia Ortodoxa-, y debido a que las mujeres recibian una mínima instrucción religiosa no conocían el hebreo.

En este sentido, en la Biblia no existe ningún mandamiento que ordene instruir a las mujeres en la Ley religiosa. Por su parte, el Talmud se muestra absolutamente contrario a la erudición religiosa femenina ${ }^{14}$, manteniéndose esta opinión a lo largo de toda la Edad Media. Así, en tanto que los niños eran enviados a la edad de cinco o seis años a una escuela, donde recibían los rudimentos de una instrucción estrictamente religiosa, las niñas permanecian en la casa y eran educadas por sus madres en sus deberes religiosos, en sus responsabilidades morales y en sus tareas domésticas, de tal forma que con frecuencia no aprendían ni siquiera a leer, ya que su misión principal en la vida sería el servicio a su marido y la procreación ${ }^{15}$.

14 «El que enseña la Torá a su hija es como si le enseñara frivolidad» (Mishná Sotá 3 , 4), y "Dejad que se quemen las palabras de la Ley, y no permitid que se enseñen a una mujer" (J. Sotá 19a).

15 Ocasionalmente se halla en la documentación alguna referencia a «maestras", que quizá se ocupaban de la educación de las niñas pertenecientes al estrato más elevado de la sociedad. 
Esta exención de la mujer judía para el cumplimiento de mandatos religiosos de carácter positivo es interpretada de manera distinta por los diversos autores: mientras unos la consideran un signo manifiesto de la inferioridad de la mujer con respecto al hombre, otros son de la opinión de que dicha exención no obedece en modo alguno a razones de indole antifeminista, sino al principio talmúdico de que quien está comprometido en un acto religioso está exento de otro simultáneo, siendo así que los quehaceres y labores domésticas son considerados como un acto propiamente religioso.

En esta línea, es altamente significativo que la mujer era quien debía velar por el cumplimiento de los preceptos religiosos de carácter doméstico, tales como la preparación de la "adafina» ${ }^{16}$ y el encendido de los candiles los viernes antes de la puesta de sol ${ }^{17}$; el lavado y purga de la carne ${ }^{18}$; el amasado del pan y la ceremonia de la "halla» ${ }^{19}$, etc. Asimismo existían otros preceptos religiosos que afectaban específicamente a las mujeres judias, como la «Tebilah" o purificación mensual ${ }^{20}$, o la «Nidda" ${ }^{21}$.

16 Debido a que en la festividad del sábado los judios tienen prohibida la realización de cualquier trabajo, incluso cocinar y encender el fuego, desde el viernes al mediodía preparaban un guiso, especie de olla, conocido como "harnín" (= caliente) y más popularmente como "adafina", que se comeria al día siguiente. Una vez preparado, y antes de la puesta del sol del viernes, se colocaba en un anafe y se cubría con brasas y rescoldos, a fin de que se mantuviera caliente hasta el sábado. Este guiso se componia básicamente de carne, garbanzos y legumbres diversas, verduras, huevos y especias.

17 Según la costumbre, los viernes por la noche los judíos encienden candiles de aceite para honrar la festividad del sábado. Dichos candiles deben arder toda la noche y no pueden ser apagados hasta que finalice el dia del sábado.

${ }^{18}$ Después de degollado el animal, con arreglo a un complejo ritual, la carne debe ser preparada según establecen las leyes rabínicas. Debido a que los judios tienen terminantemente prohibido el consumo de sangre (Levítico, XVII, 10-14, y XIX, 26; Génesis, IX, 4), la carne antes de ser cocida debe ser salada y remojada a fin de que quede totalmente seca de sangre, requisito que se hace innecesario cuando la carne se asa.

Asimismo, siguiendo el mandato biblico (Génesis, XXII), los judíos quitan todas las grasas y sebos de la carne, y en especial el nervio ciático que se halla en la articulación del muslo, nervio conocido como "landrecilla» o "quidanase" (= nervio oculto).

${ }_{19}$ Cuando las mujeres preparaban la masa para el pan cogian un pellizco de la masa y lo echaban al fuego. Esta ceremonia, conocida como "halla", obedecía al mandamiento de que las primicias de todas las masas deberian entregarse al sacerdote. Debido a que tras la segunda destrucción del Templo de Jerusalén no había sacerdotes, en recuerdo de esta prescripción biblica se echaba al fuego un pedacito de la masa.

${ }_{20}$ Antes de la boda la mujer judia debe bañarse por completo, con arreglo a un complicado ritual, para de este modo acceder totalmente purificada al matrimonio. Existe también otra ceremonia de similar significación, consistente en el baño que toda mujer judía debe tomar una vez al mes después de contraer la impureza como consecuencia de la menstruación; èsta ceremonia, conocida como «tebilah», está regulada en los versículos 
En definitiva, y a juzgar por cuanto se ha dicho aquí, cabe deducir que las obligaciones prioritarias de la mujer judía eran las de carácter doméstico, siendo su principal misión garantizar el orden y la limpieza de la casa, la alimentación de la familia y la educación de los hijos. Al mismo tiempo, y de forma idéntica a lo que acontecía con todas las mujeres en la Edad Media -ricas o pobres; cristianas, judías o musulmanas-, la mujer judía hispana se ocupaba en el hilado de la lana, del lino o del cáñamo, correspondiendo también a ella el cuidado de ancianos y enfermos.

Es muy frecuente la representación gráfica de mujeres judias hispanas en el desempeño de diversas actividades domésticas, lo que es un claro indicativo de la importancia que a ellas se concedía.

Así, pues, el papel social jugado por la mujer judía hispana a lo largo de ia Edad Media fue muy limitado, y sólo tendría realmente importancia en aquellas circunstancias en que la mujer judía debía asumir la responsabilidad en la dirección y administración de la familia como consecuencia de la muerte del marido. Aquí tiene su explicación, en mi opinión, la relativa frecuencia con que aparecen en la documentación noticias sobre viudas judías encargadas de la gestión de bienes económicos, u ocupadas en determinadas actividades profesionales, como el préstamo usurario.

Seguidamente, y a fin de completar esta panorámica sobre la mujer judía en la España medieval, me referiré a su actividad pública.

\footnotetext{
19-24 dei capítulo XV del Levitico.

Por este motivo algunas comunidades hebreas de cierta importancia contaron con baños especiales para las mujeres, como las aljamas de Toledo o Calahorra, entre otras.

${ }^{21} \mathrm{La}$ "Nidda" (= apartamiento, arredramiento) consiste en un apartamiento de siete días de duración de las mujeres respecto de sus maridos, "quando ellas estavan con sus purgaçiones. E esto deçian los sabios que avia mandado Dios por la salud y linpieça de los hombres, e porque los hijos que obiessen fuesen mas sanos e mas dispuestos, e aun mas cuerdos e rreposados, porque deçian ellos que los hijos que se engendravan estando las mugeres con su purgaçion heran "mançerim", que en rromançe quiere deçir "horneçinos", que quasi dicat hechos en forniçio, no conforme a la lei del matrimonio... E para queste apartamiento de entre marido y muger fuese muy guardado, e que non toviesen açeso el uno con el otro, pusieron e ordenaron muchos ritos, como aca haçen una varbacana para guardar la çerca mas, o un seto o balladar para mejor guardar" (Archivo Histórico Nacional, Inquisición, libro 1254, fol. 172).
} 


\section{LA MUJER JUDÍA HISPANA EN SU VIDA PÚBLICA}

La vida de la mujer judía hispana fuera del núcleo familiar puede ser analizada en una doble vertiente: su vida al margen de la comunidad hebrea, y su participación en las diversas ramas de la actividad socioprofesional. A ellas vamos a dedicar breves apartados.

\subsection{La vida de la mujer judía hispana al margen de la comunidad hebrea}

Fuera de la judería, la vida de la mujer hebrea se veía afectada por las mismas limitaciones y desigualdades de orden social y religioso que padecía el varón judío.

Entre las medidas discriminatorias que sufria la población hebrea destacan las referidas a la "vestimenta". Como es bien sabido, a partir del IV Concilio de Letrán, de 1215, scn numerosas las bulas pontificias, las disposiciones decretadas en sinodos y concilios provinciales, las ordenanzas reales, los estatutos municipales y las disposiciones de Cortes que imponen a los judios - hombres y mujeres - todo tipo de servidumbres en cuanto a la indumentaria, con una doble finalidad: que los judios fueran identificados fácilmente y así evitar, en lo posible, el contacto con la población cristiana y cualquier intento de proselitismo religioso y, por otra parte, impedir que la indumentaria de los judíos más acomodados fuera similar a la de las clases sociales poderosas, lo que obedecía a una clara motivación de índole social ${ }^{22}$.

Por todo ello, y atendiendo a las continuas quejas de los representantes de las ciudades, en sucesivas reuniones de Cortes ${ }^{23}$ - Valladolid,

${ }^{22}$ En las Cortes de Madrigal de 1438 los procuradores elevaron su protesta al rey porque las mujeres de poco estado - mujeres de oficiales, labradores y pecheros- y las judias llevaban frecuentemente tantos caudales sobre sus ropas en pieles, guarniciones de oro, aljófar y perlas, que cuando tenian que pagar los tributos al rey no había en sus casas sino paños y vestuarios.

${ }_{23}$ Véase a este respecto el trabajo de Pilar LEON TELLO, “Legislación sobre judíos en las Cortes de los antiguos reinos de León y Castilla", Fourth World Congress of Jewish Studies, Jerusalem 1968, vol. II, págs. 55-63. 
1258; Jerez, 1260; Palencia, 1313; Valladolid, 1351; Toro, 1371; Burgos, 1377; Soria, 1380 - se prohibió el uso por parte de los judíos de adornos de oro y plata y de pieles de valor, así como de cendal ${ }^{24}$, calzas bermejas y paño tinto. Por el contrario, se les obligaba a usar vestimentas de paño basto y de colores oscuros: pres, bruneta prieta, ingés o ensay negro.

Las disposiciones de Cortes eran algo más condescendientes con la mujer judia, de tal modo que le permitían el uso de paños tintos y pieles blancas, aun cuando le prohibian también terminantemente el uso de pieles de calidad, de adornos de oro y de zapatos dorados. El Ordenamiento de Valladolid de 1412 es más restrictivo, y en su artículo 14 ordena que las mujeres judías vistan con mantos largos y tocas, sin oro, cendal ni peñas, y que el precio de los paños no excediera de 30 maravedíes la vara. La cabeza la deberian llevar cubierta con mantos doblados.

Aunque respondiendo a motivaciones, lógicamente muy distintas, las autoridades religiosas judías recomendaban, y aún exigían, austeridad en el vestir. Así, en el capítulo V de las «Taqqanot» de Valladolid de 1432 (fol. 20) se recomienda que cada aljama se atenga en lo relativo a este tema a lo establecido en sus propias "taqqanot", pero de forma genérica se prohíbe el lujo excesivo, pues los judíos debian recordar que se encontraban en el exilio por culpa de sus pecados. Los autores de estas ordenanzas trataban de evitar por una parte el endeudamiento de los cabezas de familia, y por otra parte que pudieran suscitarse las envidias y los odios de la población cristiana ante el escesivo lujo en el vestir de los judíos, pues, según se dice textualmente, en algunas aljamas las mujeres exageraban más de lo debido, llevando vestiduras ricas y caras, así como joyas de oro, plata y perlas. Por todo ello prohíben que ninguna mujer, fuera soltera o novia en el año de su matrimonio, llevara vestidos de paño de oro, ni de aceituní ${ }^{25}$, ni de cendal, ni de seda, ni de chamelote ${ }^{26}$, ni forros de paños ricos, ni de paño de oro, ni de aceituní. Asimismo no podrían llevar brocados de oro ni de perlas, ni sartal ${ }^{27}$ de perlas, ni colas en vestidos que arrastraran más de una tercia de vara. Tampoco podrían vestir aljubas ${ }^{28}$ plisadas, ni mantones con cuellos altos y azul.

${ }^{24}$ El cendal es una seda de colores diversos, entre los que predominan el rojo, verde

${ }^{25}$ Seda de origen chino, de la ciudad de Tsen-Thoug (Zeitoun para los árabes).

${ }^{26}$ Tejido fuerte e impermeable.

${ }^{27}$ Collar o gargantilla.

${ }^{28}$ Túnica larga y ancha. 
y plisados, ni ropa de paño de color bermejo, ni mangas de alcandoras ${ }^{29}$, ni de aljubas de más de dos palmos de ancho. Por el contrario si se les permite llevar alhamias ${ }^{30}$ y aliharas ${ }^{31}$, y brocados, esmaltes y cintas de plata, siempre que no sobrepasen las cuatro onzas de peso.

Otras medidas tenían por objeto evitar el "contacto sexual entre judíos y cristianos". Se trata ésta de una prohibición muy antigua, de tal modo que ya el canon 78 del Concilio de Elbira, reunido a principios del siglo IV (303-309 d. de C.), castiga con pena de excomunión al cristiano casado que cometiera adulterio con una mujer judía o gentil. Algún tiempo después, en el Breviario de Alarico, promulgado en el año 506, se prohiben los matrimonios mixtos entre cristianos y judios; en el III Concilio de Toledo se prohíbe a los judíos tener mujeres o concubinas cristianas ${ }^{32}$; en la ley novena del Código de las Siete Partidas se prohíben las relaciones sexuales entre fieles de distinta religión, castigándose con la pena de muerte al judío que infringiera esta norma.

A lo largo de toda la Edad Media, numerosas constituciones eclesiásticas se esfuerzan en impedir que los cristianos tomaran como barraganas a mujeres judías o mudéjares, lanzando la pena de excomunión contra los infractores de esta prohibición. Las relaciones sexuales de cristianos no casados con judias y mudéjares se sitúan en el mismo nivel de gravedad que las relaciones sexuales con mujeres casadas, con parientes o con religiosas. Asi, pues, el amancebamiento con una mujer infiel adquiría el grado delictivo más alto en cuanto a relaciones sexuales prohibidas $^{33}$.

En esta misma línea de intento de separación de las comunidades cristiana y judia, diversas reuniones de Cortes - Sevilla, 1252; Valladolid, 1258; Jerez, 1268; Palencia, 1313; Valladolid, 1322; Valladolid, 1351; Soria, 1380; Valladolid, 1385-, asi como algunos sínodos provinciales, prohiben a las mujeres judias y mudéjares criar a niños cristianos, y a la

${ }^{29}$ Manto muy holgado que cubre desde los hombros hasta los pies. Era de seda o de lino, siendo una prenda propia de las mujeres ricas.

30 Túnica o camisa.

31 Tela de tejido delicado.

32 Véase José Luis Lacave Riaño, "La legislación antijudía de los visigodos", Simposio Toledo Judaico, Toledo, 20-22 de abril de 1972. Toledo. Universidad Complutense de Madrid-Colegio Universitario de Toledo, 1973, vol. 1, págs. 31-42.

33 Véase el trabajo de Antonio Garcia y García, "Judios y moros en el ordenamiento canónico medieval», Actas del II Congreso Internacional "Encuentro de las tres Cuituras», Ayuntamiento de Toledo, 1985, págs. 167-181. 
inversa: el Fuero Real castiga a los infractores con 50 maravedies de multa, y los cánones de los concilios provinciales con pena de excomunión. Asimismo se prohíbe a las parteras judías atender a parturientas cristianas, y a la inversa.

No obstante, estas disposiciones no debían cumplirse con regularidad, y su continua repetición en las sucesivas reuniones de Cortes es el síntoma más claro de ello. Se trata en todos los casos de medidas de carácter general, que afectaban tanto al hombre como a la mujer judía, y que tenían por finalidad última propiciar el más absoluto aislamiento de la población hebrea respecto de la mayoria cristiana, pero que, como acabo de señalar, raramente se cumplian.

\subsection{La mujer judia hispana en la actividad socio-profesional}

Y ya para concluir, si hasta aquí hemos estudiado la condición de la mujer judía en la España medieval desde el punto de vista social y familiar, esta panorámica debe completarse con un análisis de su participación en las distintas actividades socio-profesionales ${ }^{34}$.

Pese a las condiciones restrictivas que, en general, conoció la mujer judía, a través de mis propios trabajos de investigación y de numerosos estudios de diferentes autores, he podido rastrear su participación en determinados sectores profesionales. Estos coinciden a grandes rasgos con los desempeñados también por la mujer cristiana, pero con particularidades y matices que creo que quedarán de manifiesto en los distintos apartados que siguen a continuación.

3.2.1. La mujer judía en la gestión de bienes económicos y en actividades del sector primario

A través de la documentación estudiada, resulta hasta cierto punto trecuente el hallazgo de mujeres judias en la gestión de bienes econó-

${ }^{34}$ En este apartado no haré sino una presentación de las líneas generales de mi trabajo titulado "Actividades socio-profesionales de la mujer judía en los reinos hispanocristianos de la Baja Edad Media", ya citado anteriormente, y al que remito al lector interesado en profundizar en este tema. 
micos. Generalmente figuran junto a sus maridos, pero en muchas otras ocasiones aparecen ellas solas en contratos de arrendamiento o compraventa de casas o fincas rústicas, especialmente huertas, viñedos y tierras de pan llevar. Como ya señalé anteriormente, con frecuencia se trata de viudas, según se indica textualmente o se deduce del hecho de figurar junto a sus hijos y yernos. En muchas ocasiones reciben el título de "doña", lo que es indicativo de una preeminencia socio-económica. El uso de este título es comparativamente mucho más frecuente en las mujeres judias que en los hombres, $y$ en este caso concreto viene a corroborar, en mi opinión, que se trata de mujeres de edad avanzada y, con frecuencia, de viudas.

Mucho más difícil es estudiar la dedicación de la mujer judía al cultivo de la tierra, debido a la escasez de noticias documentales al respecto. Sin embargo, a lo largo de toda la Baja Edad Media son numerosas las mujeres judias que figuran como propietarias de tierras de labor, huertos y viñedos, así como las que intervienen en contratos de compraventa o arrendamiento de propiedades inmuebles. Es cierto que en algunos casos podría tratarse tan sólo de propietarias que no cultivarian directamente sus tierras, sino que lo harían mediante jornaleros, pero en otras ocasiones creo que serian elias mismas las encargadas de su puesta en cultivo, y que ayudarían a sus maridos, o a la familia en general, especialmente en las épocas de mayor trabajo en el campo, como en la época de la vendimia o de la recolección.

\subsubsection{Servicio doméstico}

Mucho más abundantes son las referencias documentales a mujeres judias ocupadas en diversas actividades del servicio doméstico, y que, generalmente, aparecen siempre como dependientes de otros judíos o de judeoconversos, y muy rara vez de cristianos, pese a que no existia prohibición para ello ${ }^{35}$.

${ }^{35}$ La prohibición era en el sentido de que los judios no pudieran tener escuderos, servidores, hortelanos o amas de cria cristianas, pero no a la inversa. 
Dentro de este sector profesional destacan fundamentalmente las criadas y sirvientas, que aparecen con relativa frecuencia en la documentación. En este sentido, era una práctica bastante usual entre las familias más débiles económicamente colocar a las niñas desde muy pequeñas en el seno de una familia acomodada donde, a cambio de la realización de sencillos trabajos domésticos, eran alimentadas y vestidas, to que suponía un considerable desahogo para la economía familiar. El compromiso se realizaba mediante un contrato individual en el que no se solía contemplar el pago de un sueldo, lo que resulta comprensible teniendo en cuenta la costumbre, muy generalizada en la época, según la cual los amos sólo recompensaban los servicios de sus criados con sus vestidos y manutención ${ }^{36}$.

Sin embargo, es muy probable que una vez cumplido el plazo fijado en el contrato, y alcanzada la mayoría de edad por la niña, se realizara un nuevo contrato en el que ya se contemplara la percepción de un salario, según otra modalidad de los contratos laborales de servicio doméstico.

Como ya señalaba anteriormente, era muy frecuente que las familias judeoconversas de condición acomodada contaran entre su servicio con criadas judías, lo que contribuía a reforzar los lazos de unión entre judíos y judeoconversos, y con frecuencia sería presentado por los inquisidores como una prueba irrefutable de judaísmo de los acusados conversos.

En este mismo apartado pueden ser incluidas también las nodrizas, dedicadas al cuidado y, fundamentalmente, a la lactancia de recién nacidos. Las nodrizas eran contratadas normalmente por medio de escrituras públicas, firmadas simultáneamente por la madre del niño, la nodriza y sus respectivos esposos. En dichas escrituras solía estipularse que la alimentación de la nodriza correría a cargo de su marido, comprometiéndose éste por su parte a abstenerse de mantener relaciones sexuales con su mujer durante el tiempo que durase el contrato, que generalmente oscilaba entre cuatro y ocho meses, aunque a veces llegaba hasta un año. La lactancia se realizaba en la casa de la nodriza o en la del niño, según constara en el contrato, y el salario, que solía fijarse a un tanto alzado, se percibía por meses ${ }^{37}$.

${ }^{36}$ Véase José María MAdurell MARIMON, "La contratación laboral judaica y conversa en Barcelona (1349-1416). Documentos para su estudio", Sefarad XVI, 1956, págs. 33-71 y 369-398, y XVII, 1957, págs. 73-102 (vol. XVI, pág. 43).

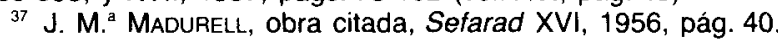




\subsubsection{Actividades artesanales y mercantiles}

Pese a que los datos que nos ofrece la documentación se hallan bastante dispersos, son ciertamente abundantes las noticias de mujeres judías dedicadas a diversas ramas de la artesanía, así como a diferentes manifestaciones de la actividad mercantil.

En muchos casos la actividad de la mujer consistía en trabajos sencillos que completaban la prioritaria dedicación al hogar. Así, era una práctica bastante frecuente entre las familias de condición acomodada que los padres, al llegar su hijas a la edad de diez o doce años, les hicieran enseñar un oficio propiamente femenino, como la costura o el bordado, a cuyo fin las colocaban con un maestro o maestra especializado, quien a cambio de la enseñanza de su oficio percibía una pequeña cuota, que con el tiempo era sustituida por el propio trabajo de la aprendiz.

Pero son también frecuentes las noticias de mujeres judías dedicadas a oficios artesanales más complejos, entre los que sin lugar a dudas adquieren una particular significación los del sector textil, de forma idéntica a lo que sucede con la mujer cristiana. De este modo, figuran en la documentación tintoreras, colchoneras, colcheras, chapineras, tejedoras, "labranderas» o costureras, pañeras, asi como también alguna propietaria de tenerías. Asimismo hay alguna referencia documental a lavanderas, que creo que pueden tratarse de las encargadas de lavar la lana, tarea que constituía el primer paso en la producción textil.

No obstante, la abundancia de noticias no debe hacernos caer en el error de conceder excesiva importancia al papel jugado por la mujer judia hispana en las actividades artesanales. Su participación se limita, de forma prácticamente exclusiva, al sector textil, e incluso en éste su presencia es mínima en relación con el hombre. Así, Madurell Marimón constata a lo largo de los siglos XIV y XV nueve judíos barceloneses dedicados al arte de la seda por ninguna judía, y diecinueve tejedores de velos judios, también de Barcelona, por tan sólo una mujer ${ }^{38}$. Del mismo modo, y fuera del sector textil, no aparece ninguna mujer entre los plateros

38 J. M. Madurell MARIMON, "El arte de la seda en Barcelona entre judios y conversos (Notas para su estudio)", Sefarad XXV, 1965, págs. 247-281. 
judíos barceloneses de la segunda mitad del siglo XIV $^{39}$, ni entre los libreros y encuadernadores judíos de esta misma ciudad entre mediados del siglo xIV y mediados del siglo $x{ }^{40}$. Es cierto que todas estas referencias proceden de un ámbito geográfico y de un período cronológico muy limitados, la Barcelona de los siglos XIV y XV, por lo que quizá las conclusiones apuntadas no puedan extrapolarse por igual a toda la Península, pero en todo caso creo que el ejemplo de Barcelona, uno de los más importantes centros comerciales e industriales de la España bajomedieval, es altamente significativo. Por otra parte, la ausencia absoluta de noticias sobre mujeres judias dedicadas a otros sectores de la actividad artesanal corrobora plenamente mis anteriores afirmaciones.

Dentro del sector mercantil las noticias son ciertamente escasas, pero suficientes para permitirnos atestiguar la participación de la mujer judía en actividades mercantiles de carácter fijo e itinerante, especialmente importantes en el primer caso. Así, debían ser relativamente numerosas las judias propietarias de tiendas, así como las regatonas, dedicadas a la venta al por menor de productos alimenticios. En este sentido existen menciones especiales de pescaderas y especieras, dedicadas respectivamente a la venta de pescado y a la preparación y expedición de medicamentos, así como de traperas y libreras, ocupadas en el comercio de paños y de manuscritos.

Mucho menores en número son las noticias sobre judías dedicadas a actividades mercantiles de carácter itinerante. No obstante, existe constancia documental de algunas mercaderas y corredoras de comercio.

\subsubsection{Medicina}

La medicina y actividades en relación con la medicina ha constituido tadicionalmente una de las dedicaciones prioritarias de los judíos, y en la

39 J. M. ${ }^{a}$ Madurell MARIMÓN, “Plateros judíos barceloneses”, Sefarad XXVII, 1967, págs. 290-298.

${ }^{40} \mathrm{~J}$. M. ${ }^{a}$ MADURELl MARIMON, "Encuadernadores y libreros barceloneses judios y conversos, 1322-1458”, Sefarad XXI, 1961, págs. 300-338, XXII, 1962, págs. 345-372, y XXIII, 1963, págs. 74-103. 
que mejor han mostrado sus dotes y conocimientos. $Y$ aunque nuevamente en número muy inferior al de los hombres, también en este campo profesional hacen su aparición las mujeres. Ciertamente no son muy numerosos los casos conocidos de mujeres médicas o cirujanas, pero si se encuentran algunas noticias en la documentación, muy en particular en el ámbito de la Corona de Aragón. Y desde luego, lo que parece indudable es que en los reinos hispanocristianos de la Edad Media fue muy superior, proporcionalmente, el número de judias médicas que el de cristianas.

Sobre este tema contamos con dos valiosas aportaciones, una de Cardoner Planas ${ }^{41}$, y otra de López de Meneses ${ }^{42}$, que han recogido en sendos trabajos noticias sobre varias judías que actuaron como médicas en la segunda mitad del siglo XIV en los distintos reinos de la Corona de Aragón. Por regla general gozaban de una privilegiada posición socioeconómica, lo que se manifiesta en la utilización del título de "Na» o "Doña". Algunas de ellas alcanzaron reconocida fama, lo que las llevó a la corte aragonesa donde intervinieron en cuestiones obstétricas entre 1368 y 1381, es decir durante el reinado de Pedro IV el Ceremonioso.

Al igual que sucede también con la mujer cristiana, es mucho más frecuente su aparición como comadrona o "partera", atendiendo no sólo a mujeres judías sino también a judeoconversas y a cristianas. Como en el caso de las médicas, algunas alcanzaron gran renombre, de forma que eran llamadas a la corte para atender a diversas mujeres de la misma.

\subsubsection{Prestamistas y arrendadoras de rentas}

El préstamo con usura constituyó también, a buen seguro, la dedjcación primordial de buen número de mujeres judías, generalmente viudas y de buena posición económica, que en la mayor parte de los casos creo que continuarian los negocios de sus maridos, y que aseguraban su

4' A. Cardoner Planas, "Seis mujeres hebreas practicando la medicina en el reino de Aragón", Sefarad IX, 1949, págs. 441-445.

${ }^{42}$ Amada LOPEZ DE MENESES, "Cinco catalanas licenciadas en medicina por Pedro el Ceremonioso, 1374-1382", Correo erudito V, núm. 37, Madrid 1957, págs. 252-254. 
situación mediante este sistema. En relación con otras actividades socioprofesionales son, ciertamente, abundantes las noticias de mujeres judias prestamistas, lo que a mi modo de ver obedece también, en parte, a los frecuentes pleitos que originaban los préstamos usurarios. Aunque existen constancia documental de grandes prestamistas judías, en la mayoría de las ocasiones se trata de préstamos de pequeñas cantidades a campesinos arruinados como consecuencia de una mala cosecha, y que se veían obligados a acudir al préstamo usurario de los judíos para poder sobrevivir. No obstante, aparecen también en la documentación referencias a importantes personajes, que llegaron a prestar muy elevadas sumas, incluso a los monarcas, como es el caso de doña Bruçete, judia de Soria, y de las mujeres o viudas de don Santo Abenabid y de maestre Symuel Çerrulla, vecinas de Ávila, quienes en 1483 prestaron a los Reyes Católicos como ayuda para la guerra de Granada las cantidades de $30.000,1.000$ y 28.000 maravedíes, respectivamente, y que en el caso de la primera y de la última se encontraban, sin duda, entre los miembros más poderosos económicamente de las aljamas soriana y abulense ${ }^{43}$.

Por el contrario, debió ser muy limitada la actuación de mujeres judías como arrendadoras de rentas. Posiblemente nula su participación en el arrendamiento de rentas reales ${ }^{44}$, aparecen esporádicamente en el arrendamiento de rentas eclesiásticas. Asimismo es probable que tuvieran alguna participación en el arrendamiento de rentas de concejiles, pero en cualquier caso la ausencia de noticias documentales al respecto es prácticamente absoluta.

\subsubsection{Plañideras}

En los reinos hispanocristianos de la Edad Media el uso de plañideras en los entierros estuvo muy extendido entre los judios, de forma que

43. Véanse Francisco Cantera Burgos, "Juderias Medievales en la provincia de Soria", Homenaje a Fray Justo Pérez de Urbel, OSB. Silos, 1976, tomo 1, págs. 445-482 (pág. 477), y Miguel Angel LADERO QueSADA, "Un préstamo de los judíos de Segovia y Ávila para la guerra de Granada en el año 1483", Sefarad XXXV, 1975, págs. 151-157.

${ }_{44}$ No figura ninguna mujer entre los ciento trece arrendadores de impuestos reales judios del siglo xv consignados por Miguel Angel LADERO QUESADA en su trabajo "Los judíos castellanos del siglo Xv en el arrendamiento de impuestos reales", Cuadernos de Historia (Anexo de Hispania), VI, 1975, págs. 417-439, y por Fritz BAER, Die Juden im Christlichen Spanien, vol. I/2. Kastilien/Inquisitionakten. Berlin 1936. 
diversos autores hispano hebraicos de época medieval hacen alusión con frecuencia a las plañideras, que recitaban lamentaciones al son del pandero. En muchas ocasiones las plañideras judias eran contratadas para entierros de cristianos, como está constatado documentalmente en la ciudad de Sevilla ${ }^{45}$.

\subsubsection{Prostitutas y barraganas}

El comercio sexual con mujeres fue corriente entre los judios desde los tiempos bíblicos, de forma que en el Antiguo y Nuevo Testamento se mencionan varios casos de mujeres prostitutas, sin que los relatos veterotestamentarios induzcan a pensar que los israelitas consideraran como especialmente censurable la conducta de estas mujeres. A lo largo de la Edad Media, la prostitución debió ser una práctica usual en todas las comunidades hispano-hebraicas de cierta importancia, pese a que la documentación no ofrece noticias al respecto. No obstante, es seguro que las prostitutas judías no atendían tan sólo a la población hebrea sino también a la cristiana, ya que, como quizá es conveniente recordar, el mantenimiento de relaciones sexuales entre miembros de diferente credo religioso solo se prohibía en el caso de judio o musulmán con cristiana, pero no a la inversa.

Por otra parte, y aunque no pueda considerarse como una actividad propiamente profesional, hay que dejar constancia de que en ocasiones las mujeres judias servian también a los cristianos como concubinas o barraganas, que gozaban de ciertos derechos reconocidos por la costumbre tradicional. Pero, en buena lógica, esta práctica era mucho más frecuente entre miembros de la misma religión, pese a que la documentación no ofrezca tampoco muchas noticias al respecto. Asimismo serían muy frecuentes estas relaciones entre judios y judeoconversos.

45 Yitzhak BAER, Historia de los judios en la España Cristiana, Madrid, Altalena, 1981, 2 vols. (Véase vol. I, pág. 244); véase también Isabel MONTES ROMERo-CAMACHO, “Notas para el estudio de la judería seviliana en la Baja Edad Media, 1248-1391", Historia. Instituciones. Documentos, 10, 1984. 


\subsubsection{Hechiceras y curanderas}

La superstición y la magia ocuparon también un importante lugar entre las costumbres y prácticas de los judios hispanos, lo que queda totalmente corroborado en el elevado número de judaizantes que aparecen en los procesos inquisitoriales de hechicerías a lo largo de los siglos XV y XVI, así como en la frecuencia con que en dichos procesos se encuentran alusiones a manuscritos hebreos de experimentos y prácticas mágicas, que generalmente tenían su origen en libros supersticiosos y cabalísticos, en los que los judíos obtenían fórmulas para la curación de todo tipo de males. La influencia de los judios en la hechicería hispana iba a ser, además, de extraordinaria importancia, ya que junto con los musulmanes sirvieron como transmisores de creencias y ritos orientales.

En definitiva, hay que resaltar el elevado número proporcional de judeoconversos que en relación con los cristianos aparecen en los procesos de hechicerías a lo largo de los siglos XV y XVI. A través de estos mismos procesos puede observarse también que es mucho mayor el número de mujeres judias y judeoconversas dedicadas a hechicerias y prácticas mágicas que el de hombres, lo que indudablemente se encuentra en estrecha relación con el hecho de que la mujer está siempre mucho más apegada a la tradición que el hombre. Esto se manifiesta entre los judeoconversos en que, por ejemplo, la mujer es generalmente la que conserva más profundamente las costumbres y ritos judíos. A ello podría unirse la afición y atracción que, según el Talmud, siente la mujer hacia todo lo oculto ${ }^{46}$.

Asi, pues, son bastante frecuentes las referencias documentales a mujeres judías hechiceras y curanderas, que encontraban en la adivinación del futuro, en el desaojamiento o en el curanderismc su medio de subsistencia. Aunque aparecen también mujeres jóvenes, en general eran pobres y viejas, en muchos casos viudas o abandonadas por sus maridos, y que con frecuencia a cambio de sus hechizos, sortilegios y curaciones no recibian un pago en metálico sino un sustento alimenticio que les permitía sobrevivir. Normalmente debian incluso acudir a otros oficios de escasa importancia, como el de lavanderas o hilanderas, o participar

46 "Las mujeres gustan de la brujería" (Yoma, 83b, y Sanh., 67a), y "Mientras más mujeres, más brujería» (Avot, II, 8). 
en los trabajos del campo, especialmente en las épocas de la vendimia y de la recolección.

Las hechiceras y curanderas judías atendían no sólo a los judíos sino también a judeoconversos, que acudían a ellas en busca de remedio para sus males, males que con frecuencia se achacaban al mal de ojo.

En resumidas cuentas, la mujer judia jugó un importantísimo papel en las prácticas de hechicería, superstición y curanderismo en los reinos hispánicos de la Edad Media, dejándose sentir su profunda influencia en los primeros tiempos de la Edad Moderna a través de las judeoconversas y judaizantes, que en buena medida conservaron las costumbres y prácticas hebreas.

\section{CONCLUSIONES}

De todo lo dicho hasta aqui pueden apuntarse varias conclusiones:

1. La familia judía se organiza según un estricto régimen patriarcal, en virtud del cual el papel de la mujer queda reducido, prácticamente, al cumplimiento de las obligaciones derivadas de su condición de esposa y madre, así como a la realización de trabajos domésticos.

2. El papel social jugado por la mujer judía en la España de la Edad Media fue muy limitado, de tal forma que sólo en algunos casos especiales y, muy en particular, cuando la muerte del marido le obligaba a asumir la responsabilidad en la dirección y administración de la familia, la mujer adquiria una auténtica relevancia.

3. Pese a las condiciones restrictivas que conocía desde el punto de vista social y familiar, la mujer judía participó en diversas actividades socio-profesionales, aun cuando su intervención fue proporcionalmente muy inferior a la del hombre. Destacan fundamentalmente en el servicio doméstico, en la artesanía textil, en la obstetricia, en la práctica de la magia y el curanderismo, y las más poderosas económicamente en el préstamo usurario. 